\title{
Gender Differential Effects of Health Status on Growth Process in sub-Saharan Africa
}

\author{
Olufunmilayo Olayemi Jemiluyi ${ }^{1}(D)$ and Abayomi Ayinla Adebayo ${ }^{2}$ (D) \\ ${ }^{7}$ Adeleke University, Ede, Nigeria \\ 2Obafemi Awolowo University, Ile-Ife, Nigeria \\ $\triangle$ Corresponding Author: Olufunmilayo Olayemi Jemiluyi, E-mail: olayemi.jemiluyi@adelekeuniversity.edu.ng
}

\section{ARTICLE INFORMATION}

Received: July 08, 2021

Accepted: August 15, 2021

Volume: 3

Issue: 2

DOI: 10.32996/jefas.2021.3.2.4

\section{KEYWORDS}

Health status, Economic growth, Gender differential, Female health, Life expectancy, sub-Saharan Africa

\section{ABSTRACT}

This study examines the gender-disaggregated effect of health status on the growth trajectory of sub-Saharan Africa region. The renewed interest in the health status economic growth nexus stems from the increasing recognition of the importance of health and gender roles in achieving economic growth and sustainable development, particularly in the developing regions of sub-Saharan Africa characterized by poor health, gender inequality and low growth. Health status is proxy by genderdisaggregated data on life expectancy at birth. The study employs the generalized method of moment (GMM) modelling technique, and the result shows that there is gendered differences in the effect of health status on the economic growth process of sub-Saharan Africa. In particular, we find that female life expectancy is positively associated with economic growth. Thus, the study recommends that efforts aimed at promoting health wellbeing in the region should be enhanced. In particular, policies geared towards bridging the gender gap in health should be enacted and implemented.

\section{Introduction}

The increasing waves of empirical and theoretical research have unveiled the unequivocal roles of health in achieving economic growth and sustainable development (Bloom, Kuhn \& Prettner, 2015; Adedeji \& Akinlo, 2016). In particular, a large body of studies investigating the macroeconomic importance of health have established that health is central to the welfare of households, profitability of firms and the overall macroeconomic performance of the economy (Bloom, Canning and Sevilla, 2004; Acemoglu \& Johnson, 2007; Bloom, Canning and Fink, 2014). Thus, there has been an increasing global acceptance of focal roles of health in achieving sustainable development and ameliorating poverty, evidenced in the remarkable growth of health aids, the inclusion of health-specific goals in global developmental programs ${ }^{2}$ and increasing volume of health research (World Bank, 2014, 2017).

In the same vein, the twin problems of poor health and low growth in sub-Saharan Africa economies have birthed a large quantum of empirical and theoretical investigations of the contributions of health to the growth process in the region. Although health indicators in most developing regions are lagging behind the highly industrialized economies of America and Europe, the statistics in sub-Saharan African countries compare less favorably with those of other developing regions. For example, in spite of the remarkable global progress in tackling communicable diseases, HIV/AIDS, tuberculosis and malaria have continued to account for a larger proportion of disability in SSA than the world as a whole (World Bank, Global Burden of Disease, 2017; UNICEF, 2016). Also, aside from the disproportionate burden of malaria, HIV/AIDS and tuberculosis, the region has continued to be plagued with diverse new and re-emerging infectious diseases such as cholera, Ebola virus disease (EVD), Lassa fever, meningococcal meningitis, monkeypox and poliomyelitis (Fenollar and Mediannikov, 2018; Davis and Lederberg, 2001). The high burden of diseases coupled with a poor healthcare system in the region had led to poor health capital characterized by high morbidity rate, high mortality rate, low life expectancy, poor maternal and child health indicators (World Development Indicators [WDI], 2019).
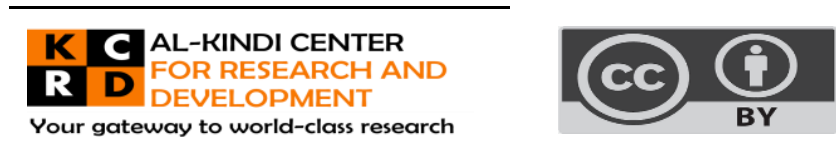

Published by Al-Kindi Center for Research and Development. Copyright (c) the author(s). This open access article is distributed under a Creative Commons Attribution (CC-BY) 4.0 license

\footnotetext{
${ }^{2}$ For example, the Millennium Development Goals (MDGs) and Post 2015 Sustainable Development Goals (SDGs)
} 
Given the predominance of agricultural activities and other jobs requiring physical stamina coupled with the absence of an effective social security system, poor health has far-reaching implications for macroeconomic performance in SSA. Different episodic outbreaks of diseases across the SSA region in recent times have exemplified that the discussion on the macroeconomic effect of health in the region cannot be overemphasized. Although there exists a rich literature on the economic growth effect of health status in sub-Saharan Africa, this study contributes to the ongoing investigation by considering gender roles in the healtheconomic growth nexus. The gender-specific effect of health on economic growth has joined the ongoing theoretical and empirical discussions on the economic growth effect of health (Mandal, Batina and Chen 2018; Hassan, Cooray and Holmes, 2017; Licumba Dzator and Zhang, 2015). There is now a shared recognition within the development community that development policies and actions that fail to address the disparities between males and females and take into account gender-specific growth determinants will have limited effectiveness and serious costs implication (World Bank, 2003). The gender perspective to the role of health in the growth process of the SSA region is important for investigation as female comprises almost half of the region's teeming population. Also, like in most countries across the globe, there are gender differences in health outcomes such as morbidity rate, life expectancy, the mortality rate (WDI, 2019). Therefore, male and female health status may have different impacts on the economic growth trajectories of SSA.

\section{Literature Review}

Using life expectancy as a measure of health capital, earlier works of Knowles and Owen (1995), Barro (1996), Bloom, Sachs, Collier and Udry (1998), Bloom and Williamson (1998) and Sachs and Warner (1997) establish that a positive relationship exists between health status and economic growth. Bhagava, Jamison, Lau and Murray (2001) investigate the health-economic growth in a panel of 70 countries using survival rate. The empirical findings based on the Random effect estimation method conclude that improved health status promotes economic growth, particularly in the poorer countries. Investigating the differences in economic growth rates between the East and South Asia countries, Bloom, Canning \& Maleney (2000) conclude that health status plays a significant role in East Asia's rapid economic growth and South Asia's slow economic progress. In another related study, Bloom, Canning \& Sevilla (2004) test the health-economic growth relation based on panel data in ten years intervals over 1960-1990. The non-linear two stages least square estimation affirms that health capital is a significant determinant of economic growth.

Furthermore, Aghion, Howitt \& Murtin (2010) assess the output growth effect of rate of improvement in health in cross-country regression involving 96 countries. Combining the Nelson-Phelps (1966) and Lucas (1988) approaches in a unified framework, the OLS estimates reveal that increased per capita outcome is associated with a higher initial level of health as well as health improvement. Swift (2010) similarly investigates the growth-inducing effect of health in a panel of studies of 13 OECD countries. The Johansen multivariate cointegration analysis covering two centuries (1820-1920 and 1921-2001) provides evidence supporting the positive effect of health on GDP and GDP per capita. In a long panel of European countries, Strittmatter and Sunde (2011) likewise corroborate the positive relationship between changes in health and economic growth. Examining the role of health in the economic growth process of a panel of European Union (EU) member countries, Alina, Donatella, Raffaella \& Nicola (2013) affirm the health-led economic growth hypothesis. However, the study also concludes that longer life expectancy with lower adult mortality rates birth elderly population with a consequent negative effect on economic growth.

In a critique of Acemoglu and Johnson (AJ) (2007), Bloom, Canning and Fink (2014) using the same dataset and instrumenting initial health rather than predicted mortality adopted by $A J$, the instrumental variable estimate shows that health improvement has a significant effect on economic growth, with an additional year in life expectancy causing between 5 percent and 15 percent rise in income over three decades. Therefore, the study hinges AJ's conclusion of negative growth-effect of health on a priori exclusion of initial health from the estimated growth model and the adoption of predicted mortality change instrument, which has no predictive power for health improvement. Somayeh, Teymoor \& Mina (2013) adopt the fixed-effect method to examine the growtheffect of health in a two-group panel of 14 developing countries and 16 developed countries. The results indicate that improved health status has a significant positive impact on economic growth in both groups of countries.

In a panel study comprising of 141 developing countries, Ngangue and Manfred (2015) likewise explore the association between improvement in health and economic growth using dynamic panel estimators including fixed effect, instrumental variable and GMM over the period 2000-2013. The study establishes that better health status plays a significant positive role in the economic growth process. Stratifying the countries into income group, the findings show that while the relationship is consistent for the lowand high-income, the effect is not significant for the middle-income countries.

Ali and Khurram (2017) investigate the contributions of the demographic factors and population health in the phenomenal increase in South Asia's GDP in the last two decade. Using the fixed and random effect estimation techniques, the study upholds the growthenhancing effect of population health, asserting that improvement in health signaled by increasing life expectancy and reduction in mortality rates plays significant role in the growth of the economies of the South Asian countries, and hence their development. 
In a survey of literature, Ndedi, Metha \& Nisabwe (2017) examine the role of health in economic development. In affirmation of the health-led growth hypothesis, the conclusion suggests that increase in funding for health promote economic growth.

In spite of the large body of evidence in favour of the pro-growth effect of health, some studies assert that health does not lead to significant growth in the economy. For example, Caselli, Esquivel and Lefort (1996), using a panel data in five years interval over 1960-1985, show that additional year in life expectancy does not translate to a significant increase in economic growth. Similarly, the findings stemming from the OLS and instrumental variable analysis of Acemoglu and Johnson (2007) assert that although increased life expectancy is associated with significant rise in population, the analysis shows no evidence of a significant effect of improved health on GDP growth. Also, Lehmijoki and Palokangas (2011) conclude that increase in life expectancy only raises the population size, thereby causing a dilution of the income per capita. Based on an empirical examination of the hypothesis of whether the decreasing rate of mortality induces growth, Fiaschi and Fioroni (2015) assert that without accompanying technological progress, the decline in mortality rate due to improved health status will only birth a Malthusian regime with implications of low GDP growth and reduced GDP per capita.

Moreover, a sizeable body of the literature provides evidence on sub-Saharan Africa. Analyzing the focal role of human capital in economic development in the continent of Africa, Eggoh, Houeninvo \& Sossou (2015) examine the effect of health on economic growth in a panel of 49 African countries. Both the OLS and GMM estimates reveal that public spending on health has a negative effect on economic growth, while health proxied by life expectancy and survival to age 65 has positive effects of small magnitude. Testing for the threshold effect of longevity on productivity and economic growth in a panel of sub-Saharan Africa, Adedeji and Akinlo (2016) find that longevity is an increasing function of labour productivity and economic growth, with significant positive threshold effects at ages 46.7 years on labour productivity and 67.5 years on economic growth. In another contribution to the SSA region, Waziri, Nor, Abdullahi \& Adamu (2016) assess the economic growth impact of the HIV/AIDS scourge in SSA. Analyzing the effect of the disease on life expectancy and the implication for growth in a decade from 2002-2012, the GMM estimates show that HIV/AIDS epidemic is growth-inhibiting in the region, with a 10 percent increase in its prevalence rate accounting for a decline of 0.14 percent in GDP growth. Also, assessing the relationship for the SSA region in a panel of 36 SSA countries using the GMM estimator, Aboubacar and $\mathrm{Xu}$ (2017) establish a similar finding of a positive association between spending on health and economic growth.

Accounting for the possible reasons for divergence of findings, a strand of the literature argues that the result's diversity might be due to the assumption of linear relationships characterizing the literature. Thus, Hansen (2012), considering the possibility of non-linearity in the relationship, investigate the nexus in a panel of 119 countries over a period of four decades (1940-1980). Confirming the existence of non-linearity in the relationship, the study concludes that the assumption of linear relationship impedes the accurate analysis of the relationship and that health contributes robustly to economic growth within a non-linear framework. Criticizing Acemoglu and Johnson (2007)'s finding of no significant effect of improved health on economic growth, Desbordes (2011) argues that the AJ's conclusions might have stemmed from functional form misspecification based on the assumption of a linear relationship. Estimating the relationship within a nonlinear framework using the same dataset, the instrumental approach results indicate that life expectancy is positively correlated with GDP, and hence GDP per capita, conditional on each country's initial level of life expectancy. Estimating a non-linear model and focusing on the role of demographic transition in the nexus between health capital and growth of economic output, Cervellati and Sunde (2011) find that health has a strong positive effect on income per capita in post-transitional countries and a negative causal impact in pre-transitional economies. In a recent study Khalim (2017) test a non-linear quadratic effect of life expectancy on output growth in a panel of 164 countries. The cross-section random effect analysis establishes a non-linear quadratic positive effect of health on economic growth, with a maximum turning point of 66 years.

Furthermore, a review of the literature shows that there exists a tiny but growing strand of the literature examining the gendered differences in the relationship between health status and economic growth. Disaggregating the role of health by gender, Hassan and Cooray (2012) estimate the disaggregated effect of male and female health on economic growth in a panel of 83 countries. Accounting for endogeneity with different estimators and instruments, the study suggests that while improvement in male health is growth-inducing, female health has a negative effect on output growth. Licumba et al., (2015) study the gender differential effect of health in a panel of Southern Africa Development Community (SADC) member states. Using the fixed effect estimation method, the study finds that while both male and female life expectancies are positively related to economic growth, the magnitude is relatively higher for males.

In a cross-country panel of 127 countries, Mandal et al. (2018) test for the existence or otherwise of gendered difference in the effect of education and health dimensions of human capital on economic growth between 1975 and 2010. Adopting the dynamic panel model of GMM and classifying the countries into developed and developing countries, the study shows that the growth effect of health differs across gender. Specifically, female health is correlated with economic growth in the developed countries, 
while male health is associated with economic growth in developing countries. More recently, Jemiluyi and Alao-Owunna (2020) examined the health-economic growth nexus in Nigeria, bearing in mind the possibility of gendered differences in the relationship. The Fully Modified OLS result showed that male health correlates with economic growth in Nigeria while there is no evidence of the significant effect of female health on economic growth.

\section{Method and Analytical Framework}

\subsection{Analytical Framework and Empirical Model}

Following existing studies on the human capital-growth literature such as Lucas (1988), Romer (1990), Barro (1996), Bloom et al. (2004), a theoretical model based on the endogenous growth model was developed for the investigation of the gender differential effect of male and female health status on economic growth in SSA. Specifically, the empirical model is built on the production function approach of Bloom et al. (2004). Thus, a Cobb Douglas production function is re-specified as in equation (1) to incorporate the role of human capital into the growth process as argued by Nelson and Phelps (1966) and Lucas (1988). ${ }^{i}$

$$
Y_{t}=A_{i t} K_{i t}^{\alpha} L_{i t}^{\beta} e^{\theta h_{i t}}
$$

The effect of the human capital term on output is expressed as the power of an exponential. So, health is captured in the human capital term $\theta h$. From equation (1), output $Y$, therefore, depends on total factor productivity $A$, physical capital $K$, labour $L$ and human capital $h$. An equation for the log of output in country $i$ at time $t$ is obtained by the logarithmic transformation of the aggregate production function into an econometrical equation. So, equation (2) becomes;

$$
y_{i t}=\alpha_{t}+\alpha k_{i t}+\beta l_{i t}+\theta h_{i t}+v_{i t}
$$

Following Hassan et al. (2012) adaptation of the production function growth model, this study modified equation (4) by disaggregating the human capital factor $\theta h$ into two aggregate components of health based on genderii. Therefore, the standard model for this study is presented in equation (4) as follows:

$\Delta y_{i t}=\phi_{0}+\phi_{1} \Delta y_{i t-1}+\phi_{2} \Delta$ mlex $_{i t}+\phi_{3} \Delta$ flex $_{i t}+\phi_{4} X_{i t}+\Delta v_{i t}$

where $y_{i t}$ is the growth rate of per capita GDP, mlex and flex are male and female life expectancy at birth respectively and $X_{i t}$ is a vector of control variables.

Following extant literature, health status is measured by life expectancy, while economic growth is denoted by per capita GDP growth rate. Moreover, in order to ensure robust analysis and to assess the strength of independent connections between health status and economic growth, gross fixed capital formation (GFCF), labour force participation rate (LFP) and dependent share of the population (POP) are included in the model to control for other factors associated with economic growth.

All data are sourced from the World Development Indicators (WDI) 2019 edition, an online database of the World Bank. The analysis is limited to thirty-five SSA countries due to data availability. For the estimation of the empirical model, the study adopted the panel data analysis method of analysis. Panel models have been found efficient in controlling for the problem of heterogeneity inherent in most panel studies. In addition, aside from its capacity to mitigate the effects of multi-collinearity, panel models also improve the efficiency of estimation and measure the effects that could not be identified with time series models. Thus, the study employs the Generalized Method of Moment (GMM) method which has been adjudged more efficient than most other techniques of estimating the coefficients of panel data model such as the pooled OLS and the fixed and random effect estimators, particularly in situations when the problem of endogeneity, simultaneity and omitted variables are likely to arise (Wooldridge, 2001; Roodman 2006)

In addition, the estimates of GMM are robust in the presence of non-normality and temporal dependencies in the data. They are consistent and asymptotically normally distributed under suitable regularity conditions (Arellano and Bond, 1991).

\section{Results and interpretation}

The results of the GMM regression are presented in Table 1. Specifically, the results show the coefficients, direction and significance of the effects of the explanatory variables on economic growth in SSA. The relationship between female life expectancy is positive and significant at a 5 percent level of significance, while the growth effect of male life expectancy is negative and significant at 5 percent. In particular, a year increase in male life expectancy will result in a decline of 1.31 percent in output growth at 5 percent level of significance, while a year increase in the life expectancy of females will lead to a 1.12 percent increase in output at 5 percent significance level.

Table 1: Summary of Two-step System-GMM Dynamic Panel Data Estimation of Gender Disaggregated Effect of Health Status on Economic Growth 


\begin{tabular}{|c|c|c|}
\hline \multicolumn{3}{|c|}{ Dependent variable: Per Capita GDP Growth Rate } \\
\hline Independent variables & Coefficients & z-statistics \\
\hline GDPCG $_{t-1}$ & $0.167^{\star}$ & 3.64 \\
\hline Lmlex & $-1.305^{* *}$ & -2.00 \\
\hline Lflex & $1.121^{\star *}$ & 1.86 \\
\hline GFCF & $0.255^{*}$ & 8.05 \\
\hline LFP & -0.035 & 0.20 \\
\hline POP & 0.184 & 1.06 \\
\hline Wald Chi(2) test: 204.2 & \multicolumn{2}{|c|}{ Intsrument rank: 19} \\
\hline M1(p-value): & \multicolumn{2}{|c|}{ J-statistic: } \\
\hline M2(p-value): & \multicolumn{2}{|c|}{ No of observations: 728} \\
\hline
\end{tabular}

Note: ${ }^{*}{ }^{* *}$ and ${ }^{* *}$ indicate significance at 1 and 5 percent level respectively. Heteroscedasticity-adjusted z-values are reported correspondingly for each estimated coefficient values. $\mathrm{m} 1$ and $\mathrm{m} 2$ are the Arellano and Bond (1991) first and second-order serial correlation tests ( $\mathrm{H}_{0}$ : no serial correlation). J-statistic is the Hansen tests for over-identifying restrictions.

Although the results corroborate the findings of Hassan et al. (2017), Licumba et al. (2016) and Hassan et al. (2012), which have established gendered differences in the effect of health status on economic growth, the obtained results are contrary to expectation for SSA where the labour force is dominated by men (WDI, 2019). However, the results might be due to some reasons, some of which are peculiar characteristics of the region. For example, in most modern populations of the world, women are considered healthier than men, as evidenced by diverse measures of health in favour of women (WDI, 2019; Institute for Health Metric and Evaluation [IHME], 2017). Globally, women have lower mortality across almost all ages. Women have higher survival rates even in extreme conditions such as famine and epidemic, and hence live a longer, healthier life span than men (Bloom, et al., 2015; Guerra-Silveira and Abad-Franch, 2013).

Similarly, both theoretical and empirical evidences abound to the sex differential in the prevalence of diseases particularly infectious diseases among males and females. Men bear a higher burden of infectious diseases which are major causes of illness and death in SSA (Bernin and Lotter, 2014). For example, men are more prone to contracting and dying from tuberculosis than women. According to the IHME data and findings (2017), among the HIV-negative population in SSA, males make up most TB cases and die at higher rates (64.7 percent) than females, while the proportion is far higher among the HIV-positive population. Although women's share of the population living with HIV is relatively higher than men's, men still bear a significant proportion of the burden of the disease and more men die from HIV due to co-infection with TB (UNAIDS, 2017; WDI, 2019). Other male-biased diseases common to the SSA region include meningococcal meningitis which has remained a recurring infectious disease particularly in the western part of the sub-region and hepatitis B accounting for about 100,000 deaths annually. Moreover, the results may suggest the health-risky behaviour of men such as an uncontrolled appetite for alcohol consumption, risky sexual behaviour and smoking which greatly hamper their health and hence their cognitive ability (Odimegwu and Mutanda, 2017). Hence, coupled with the poor healthcare systems in the sub-region, men are likely to be sicklier in SSA with the consequential implications of hampered cognitive ability, increased rate of absenteeism from work and low productivity stemming from inability to participate productively in the economy. So, an additional year in male life expectancy might not have translated into an increase in output growth due to the inability to channel the increase in life span into productive activities that are crucial for the economy's growth.

For the positive economic growth effect of female health, in addition to the general healthier nature of women evidenced in their high survival rates and longer healthy life span, the result might not be unconnected to the increasing recognition of females' role in achieving sustainable development which has led to significant global attention towards improving females' quality of life. For instance, the global campaign for women's development over the past decades has stimulated increased female enrolment in education and training as well as participation in economic activities, which are critical for economic growth (International Monetary Fund (IMF), 2018). Also, female participation in entrepreneurial activities is higher in SSA than any other region of the world; hence MDGs and SDGs-sponsored health interventions aimed at women development in the region have led to an increased number of healthy women engaging in small and medium-sized enterprises (SMEs) which has been empirically established as significant drivers of economic growth in the developing economies (Galindo and Mendez, 2014; Omoruyi, Olamide, Gomolemo \& Donath, 2017).

The estimated results show that economic growth in the previous year had a statistically significant positive effect on the growth of the economy in the current year at $p<0.001$. This indicates the importance of the initial level of income per capita in the current income per capita in the sub-region of SSA. This also justifies the adoption of a dynamic panel data model for this study rather than the static estimation techniques such as the OLS, fixed and random effects methods. The investment variable (proxy by gross fixed capital formation) also has a significant positive effect on economic growth, while both the rate of participation in the labour force and share of dependent population age 1-14 years have insignificant effects on economic growth 
The reported Wald chi-squared statistic of 204.2 show the joint significance of all the included explanatory variables in explaining the variations in economic growth. Moreover, the null hypothesis $\left(\mathrm{H}_{0}\right)$ of no serial correlation is accepted at both the first (AR(1)) and second-order (AR(2)). Similarly, the reported J-statistics of Hansen test for over-identifying restrictions confirm the validity of the selected instruments for the model. Also, as Roodman (2006) and Mileva (2007) suggested, the number of instruments in each regression is greater than the number of estimated coefficients but lesser than the number of groups in the panel.

\section{Conclusions and policy implications}

This paper evaluates the gender differential effect of male and female health status on economic growth in sub-Saharan Africa. The study's objective is pursued using panel data of thirty-five SSA countries and 2-step system GMM estimator. The result establishes gender differential in the effect of health status on economic growth. Specifically, an additional year in female life expectancy is associated with an increase in economic growth, while an additional year in male life expectancy is negatively related to economic growth. Furthermore, during the period assessed in the study, investment measured by gross fixed capital formation has a strong positive effect on economic growth, while population aged 1 to 14 years and rate of participation in the labour force have insignificant effects on economic growth.

Based on the findings stemming from this study, the following policy suggestions are recommended. First, the national governments of SSA countries and developmental health partners should intensify efforts to raise the health quality standards of women in the region by paying adequate attention to female-specific health needs. Similarly, policy actions to enhance male health should be promoted across the region so that additional years in male life expectancy can positively impact the growth process of the SSA countries' economies.

\section{Acknowledgement and Declaration of Conflicting Interest: Nil}

Funding: The authors disclosed the receipt of the following financial support for the research. This work was supported by the African Economic Research Consortium (AERC) [grant number TT19005]

\section{References}

[1] Aboubacar, B., \& Xu, D. 2017. The Impact of health expenditure on economic growth in sub-Saharan Africa. Theoretical Economics Letters, 7(1), 615-622. http://doi.org/10.4236/tel.2017.73046

[2] Acemoglu, D., \& Johnson, S. (2007). Disease and development: the effect of life expectancy on economic growth. Journal of Political Economy, 115(6), 925-985.http://dx.doi.org/10.1086/529000

[3] Adedeji, A., \& Akinlo, A. (2016). Infectious diseases, longevity and labor productivity in sub-Saharan Africa. Africa Development Review, 28(1), 127-139. https://doi.org/10.111/1467-8268.12172

[4] Aghion, P., Howitt, P., \& Murtin, F. (2010). The relationship between health and growth: when Lucas meets Phelps. Review of Economics and Institutions, 2(1), 1-24. https://doi.org/10.5202/rei.v2i1.1.

[5] Akobeng, E. (2017). Gross capital formation, institutions and poverty in Sub-Saharan Africa. Journal of Economic Policy Reform, 20(2), 136164. DOI: $10.1080 / 17487870.2015 .1128833$

[6] Alina, C., Donatella, F., Raffaella, M., and Nicola, M. (2013). Demographics and health in the EU 27 development process. Procedia - Social and Behavioural Sciences, 93(1), 704-708.

[7] Ali, S., \& Khurram, S. (2017). Impact of demographic and health factors on GDP growth of South Asian Countries. International Journal of Academic Research in Business and Social Sciences, 7(3).

[8] Bernin, H., \& Lotter, H. (2014). Sex bias in the outcome of human tropical infectious diseases: influence of steroid hormones. Journal of Infectious Diseases, 209(S3), 107-113.

[9] Bhagava, A., Jamison, D., Lau, L. \& Murray, Christopher (2001). Modelling the effects of health on economic growth. Journal of Health Economics, 20(3), 423-440.

[10] Barro, R. 1996. Determinants of economic growth: a cross country empirical study. Cambridge MA, The MIT Press, 1997.

[11] Bloom, D., \& Williamson, J. (1997). Demographic transitions and economic miracles in emerging Asia. The World Bank Economic Review, 12(3), 419-455.

[12] Bloom, D., Sachs, J., Collier, P., \& Udry, C. (1998). Geography, demography and economic growth in Africa. Brookings Papers on Economic Activity, 1998(2), 207-295.

[13] Bloom, D., Canning, D., \& Maleney, P. 2000. Demographic change and economic growth in Asia. Population and Development Review, 26(1), 257-290.

[14] Bloom, D., and Canning, D. (2004). Health and economic growth: reconciling the micro and macro evidence. Center on Democracy, Development, and Rule of Law, Stanford Institute of International. Studies, Stanford, CA. Working Paper No.42. http://cddrl.stanford.edu.

[15] Bloom, D., Canning, D., \& Fink, G. (2014). Disease and development revisited. Journal of Political Economics, 122(6), 1355-1366.

[16] Bloom, D., Kuhn, M., \& Prettner, K. (2015). The Contribution of female health to economic development. National Bureau of Economic Research (NBER) Working Paper 21411.

[17] Cervellati, M., \& Sunde, W. (2011). Life expectancy and economic growth: the role of the demographic transition. Journal of Economic Growth, 16(2), 99-133.

[18] Caselli, F., Esquivel, G. and Lefort, F. (1996). Reopening the convergence debate: a new look at cross-country growth empirics. Journal of Economic Growth, 1(3), 363-389. 
[19] De La Fuente, Á., \& Domenéch, A. (2000). A human capital in growth regressions: how much difference does data quality make? Economic Department Working Paper No 262, Paris: OECD, 2000 (ECO / WKP (2000) 35).

[20] Desbordes, R. (2011). The non-linear effects of life expectancy on economic growth. Economics Letter, 112(1), $116-118$.

[21] Eggoh, J., Houeninvo, H., \& Sossou, G. (2015). Education, health and economic growth in African countries. Journal of Economic Development, 40(1), 93-111.

[22] Fenollar, F., \& Mediannikov, O. (2018). Emerging infectious diseases in Africa in the 21st century. New microbes and new infections, 26, S10S18. https://doi.org/10.1016/j.nmni.2018.09.004

[23] Fiaschi, D., \& Fioroni, T. (2015). Adult mortality and modern growth. Department of Economics University of Verona Working Paper Series No 22.

[24] Galindo, M., \& Mendez, M. (2014). Entrepreneurship, economic growth and innovation: are feedback effects at work? Journal of Business Research, 67(5), 825-829.

[25] Guerra-Silveira, F., \& Abad-Franch, F. (2013). Sex bias in infectious disease epidemiology: patterns and processes. PLoS One, 8(4): e0062390.

[26] Hansen, C. (2012). The relation between wealth and health: evidence from a world panel of countries. Economics Letters, 115(1), 175-176.

[27] Hassan, G., \& Cooray, A. (2012). The effect of female and male health on economic growth: cross-country evidence within a production function framework. Proceedings of the $41^{\text {st }}$ Australian Conference of Economists (pp. 1-29). Melbourne: Victoria University.

[28] Hassan, G., Cooray, A., \& Holmes, M. (2017). The effect of female and male health on economic growth: cross-country evidence within a production function framework. Empirical Economics, 52(2), 659-689.

[29] Institute of Medicine (US) Forum on emerging infections; Davis JR, Lederberg J, editors. Emerging Infectious Diseases from the Global to the Local Perspective: A Summary of a Workshop of the Forum on Emerging Infections. Washington (DC): National Academies Press (US); 2001. 3, Emerging Infections in Africa. Available from: https://www.ncbi.nlm.nih.gov/books/NBK99567/

[30] Jemiluyi, O.O. \& Alao-Owunna, I. (2020). A reconsideration of the health status - economic growth nexus: evaluation of the gender differential effect in Nigeria. Eurasian Journal of Economics and Finance, 8(4), 217-230.

[31] Khalim, N. (2017). The quadratic effect of life expectancy on economic growth. Proceeding 2nd ISI Regional Statistics Conference, 20-24 March 2017, Indonesia (Session CPS17).

[32] Knowles, S., and Owen, P. (1997). Health capital and cross-country variation in income er-capita model. Economic Letters, 48(1), 314-328.

[33] Lehmijoki, U., and Palokangas, T. (2015). The long-run effects of mortality decline in developing countries. IZA Discussion Paper No. 5422.

[34] Licumba, E., Dzator, J., and Zhang, X. (2015). Health and economic growth: are there gendered effects?: evidence from selected Southern Africa Development Community Region. Journal of Developing Areas, 50(5), 215-227.

[35] Lucas, R. (1988). On the mechanics of economic growth. Journal of Monetary Economics, 22(1), 3-42.

[36] Mandal, B., Batina, R., \& Chen, W. (2018). Do gender gaps in education and health affect economic growth? a cross-country study from 1975 to 2010. Health Economics, 27(5), 877-886.

[37] Mankiw, N., Romer, D., \& Weil, D. (1992). A contribution to the empirics of economic growth. Quarterly Journal of Economics, 107(2), 407437.

[38] Mileva, E. (2007). Using Arellano-Bond dynamic panel GMM estimators in stata. Retrieved from http://www.fordham.edu/academics/programs at fordham /economics/index.asp

[39] Nelson, R., \& Phelps, E. (1966). Investment in humans, technological diffusion, and economic growth. The American Economic Review, $56(1 / 2), 69-75$.

[40] Ngangue, N., \& Manfred, K. (2015). The impact of life expectancy on economic growth in developing countries. Asian Economic and Financial Review, 5(4), 653-660.

[41] Odimegwu, C., \& Mutanda, N. (2017). Covariates of high-risk sexual behaviour of men aged 50 years and above in sub-Saharan Africa. Journal of Social Aspect of HIV/AIDS Research Alliance. https://doi.org/10.1080/17290376.2017.1392340

[42] Omoruyi, E., Olamide, K., Gomolemo, G., \& Donath, O. (2017). Entrepreneurship and economic growth: does entrepreneurship bolster economic expansion in Africa? Journal of Socialomics, 6(4), 219. https://doi.org/10.4172/2167-0358.1000219

[43] Renton, A., \& Lintott, M. (2012). Economic growth and decline in mortality in developing countries: an analysis of the World Bank development datasets. Public Health, 126 (1), 551-560.

[44] Romer, P. (1990). Human capital and growth: theory and evidence. NBER Working Paper 3173.

[45] Roodman, D. (2006). How to do Xtabond2: an introduction to difference and system GMM in stata. Centre for Global Development (CGD) working paper No 103.

[46] Somayeh, H., Teymoor, M., \& Mina, S. (2013). Effect of health on economic growth: a panel data study of developed and developing countries. European Online Journal of Natural and Social Sciences, 3(2), 1273-1278.

[47] Strittmatter, A., \& Sunde, W. (201). Health and economic development: evidence from the introduction of public health care. IZA Discussion Paper 5901.

[48] Swift, R. (2011). The relationship between health and GDP in the OECD Countries in the very long-run. Health Economics, 20(3), 306-322. Doi: $10.1002 /$ hec. 1590 .

[49] Uneze, E. (2013). The relation between capital formation and economic growth: evidence from sub-Saharan African countries. Journal of Economic Policy Reform, 16(3), 272-286. DOI: 10.1080/17487870.2013.799916

[50] UNICEF (2016). The state of the world's children: a fair chance for every child. Retrieved from: https://www.unicef.org/publications/files/UNICEF SOWC 2016.pdf

[51] Waziri, S., Nor, N., Abdullah, N., \& Peter Adamu. (2016). Effect of the prevalence of HIV/AIDS and the life Expectancy rate on economic growth in SSA Countries: difference GMM approach. Global Journal of Health Science, 8(4), 212-220.

[52] Wooldridge, J. (2001). Applications of Generalized Method of Moments Estimation. Journal of Economic Perspectives, 15(4): 87-100.

[53] World Bank (2003). Gender and growth in Africa: issues and evidence. Washington DC: The World Bank.

[54] World Bank (2014). Poverty and health. Retrieved from:http://www.worldbank.org/en/topic/health/brief/poverty-health 
[55] WHO (2015). Success factors for women and children's health: Rwanda. Retrieved from: http://www.who.int/pmnch/successfactors/en/

[56] World Bank (2017). Sustainable development goals (SDG) atlas: no poverty. Retrieved from: http://datatopics.worldbank.org/sdgatlas/SDG01-no-poverty.html 